\title{
The nutritional potential of grape by-products from the area of Slovakia and Austria
}

\author{
Ondrej Hanušovský1*, Branislav Gálik, Daniel Bíro', Milan Šimko, Miroslav Juráček¹, Michal Rolinec ${ }^{1}$, \\ Luboš Zábranský², Christian Philipp ${ }^{3}$, Reinhard Puntigam ${ }^{4}$, Julia Andrea Slama ${ }^{4}$, Martin Gierus ${ }^{4}$ \\ ${ }^{1}$ Department of Animal Nutrition, Faculty of Agrobiology and Food Resources, Slovak University of Agriculture in Nitra, ${ }^{2}$ Department of Animal \\ Husbandry Sciences, Faculty of Agriculture, University of South Bohemia in Czech Budejovice, ${ }^{3}$ Federal College and Research Center for \\ Viticulture and Pomology, Klosterneuburg, Austria, ${ }^{4}$ Institute of Animal Nutrition, Livestock Products, and Nutrition Physiology, Department of \\ Agrobiotechnology, University of Natural Resources and Life Sciences, Vienna, Austria
}

\section{A B S TR A C T}

Current experiments with farm animals showed that it is possible to use grape by-products as a source of nutrients in animal nutrition. In the present experiment, we hypothesize that one reason for the variation among feeding trials, besides production steps affecting byproduct quality in winery, the variation among cultivars may have substantial contribution. The main aim of this study was to analyse grape pomace and stems from the area of Slovak Republic and Austria to evaluate their nutritional value for animals. In total, 54 samples of 3 grape varieties from 6 different locations were analysed. In each variety basic nutrients, antioxidant activity, total phenols, condensed tannins and proteins participation was determined according to standard analytical methods. The results show that the grape pomace had the highest ratio of crude proteins, crude fat and crude fibre with the solid concentrations of sugars, except of variety from red grape. Then, the grape stem is characterised with balanced content of crude protein, crude fibre and nitrogen free extracts with residual sugars and the highest antioxidant activity. By-products from the winery production have average nutritional value because of higher content of lignin that could be limiting factor for the digestibility. Neverthelles, there are interactions between the fibre fractions, condensed tannins, total polyphenols and antioxidant activity. Analysed data shows, that grape by-products have a potential in animal nutrition as a source of bioactive compounds, however there exists differences between the locations and varieties.

Keywords: Antioxidant activity; Grape bunch; Grape pomace; Grape stem; Nutritive value; Polyphenols

\section{INTRODUCTION}

Winemaking produces annually millions of tons of by-products, which are valuable resources having many potential uses, also in animal nutrition (Domínguez et al., 2016). The most of components with nutritive value come directly from vineyard in two main winemaking by-products: grape pomace and stems (Makris et al., 2007). Small proportions of the grape pomace that is produced during the process of winemaking in the wine industry is used for the ethanol production. Oil from grape seed is used mostly as food ingredients (Negro et al., 2003; Fontana et al., 2013; Álvarez-Casas et al., 2014). Shinagawa et al. (2017) found in grape seed oil higher content of linoleic acid (72.19 - 75.02\%) which is health-benefitting fatty acid, followed by oleic acid $(14.80-17.20 \%)$ and then palmitic acid (6.26 - 6.70\%) with PUFA from $72.67 \%$ to $75.38 \%$, MUFA from 14.80 to $17.34 \%$ and SFA content from 9.72 to $10.22 \%$. In contrary, olive oil has higher content of oleic acid (60.76 - 62.74\%), then linoleic acid (13.22 - 18.45\%) and palmitic acid (15.19 - 18.71\%) characterized with higher MUFA content (62.42 - 64.30\%), lower PUFA content (13.61 - 19.20\%) but higher SFA content (18.37 - 22.09\%) (Giuffrè et al., 2017a). Furthermore, in sunflower seed oil the highest content of linoleic acid (50.89 - 55.78\%), followed by oleic acid $(32.37-35.69 \%)$ and palmitic acid (7.47 - 6.44\%) with the content of PUFA from 52.49 to $56.24 \%$, MUFA from 32.77 to $36.55 \%$ and SFA from 10.99 to $12.54 \%$ was observed (Giuffrè et al., 2017b). In contrary, peanut seed oil had the highest content of oleic acid (44.61 - 50.94\%), then linoleic acid (29.92 - 35.07\%) and palmitic acid (8.42 - 10.90\%). Then, the MUFA content in peanut seed oil was from 45.53 to $51.87 \%$,

\footnotetext{
*Corresponding author:

Ondrej Hanušovský, Department of Animal Nutrition, Faculty of Agrobiology and Food Resources, Slovak University of Agriculture in Nitra.

Tel: +421/37/64143201. E-mail: ondrej.hanusovsky@uniag.sk

Received: 13 May 2019; $\quad$ Accepted: 11 December 2019
} 
PUFA from 30.01 to $35.35 \%$ and SFA from 16.56 to $20.84 \%$ (Giuffrè et al., 2016). Grape pomace has high acidity and is suitable for silage making, thus is used as a feed for animals, although its digestibility is low because of high lignin content (Kammerer et al., 2005).

The nutritional composition of grape samples shown that it varies widely, depending on the grape variety, grape origin and the conditions of fertilization (Brenes et al., 2016). Also, the nutritive value of grape by-products is determined by ratio of seeds and pulps (Guerrera-Rivas et al., 2016). Feeding of grape by-products showed different results in experiments with farm animals. For instance, feeding of grape seeds extracts and grape pomace on the one hand did not affect the growth performance of chickens (Hughes et al., 2005; Brenes et al., 2008; Chamorro et al., 2012; Chamorro et al., 2015). On the other hand, in the experiment of Liu et al. (2014), growth performance was improved. This is because grape pomace fed to poultry reduced meat lipid oxidation (Brenes et al., 2008; Iqbal et al., 2015), oxidation stress during coccidiosis (Wang et al., 2008), and increased content of PUFA in meat (Chamorro et al., 2015). In experiments with pigs, feeding fermented grape pomace or grape marc meal improved nitrogen digestibility and growth performance, modified the pattern of fatty acids in subcutaneous fat (Yan and Kim, 2008), improved the gain to feed ratio (Fiesel et al., 2014) and reduced E. coli in feaces of weaned pigs (Verhelst et al., 2014). However, in experiments with rabbits no effect on growth performance (Tortuero et al., 1994; Nicodemus et al., 2007) was observed. In contrast, Motta-Ferreira et al. (1996) observed that feeding grape pomace to rabbits leads to linear decrease of gain to feed ratio and improved digestible crude protein use. Nielsen et al. (2004) and Nistor et al. (2014) did not observed changes in milk yield and milk composition by feeding grape pomace to dairy cows. Belibasakis et al. (1996) found that grape marc feeding did not affect DM intake, milk composition and milk yield. Dried or ensiled grape marc improved content of MUFA, PUFA and linoleic acid in dairy milk (Moate et al., 2014). In beef cattle, feeding of grape marc resulted in decreasing live-weight gains (Manterola et al., 1997). Feeding of grape pomace to fattening lambs decreased the rate of the nutrients digestibility because of high fiber, lignin and tannin presence (Nistor et al., 2014). However, addition of grape pomace improved positively ruminal parameters and retained nitrogen in sheep (Abarghuei et al., 2010). Current experiments with farm animals showed that it is possible to use grape by-products as a source of nutrients in animal nutrition. In the present experiment, we hypothesize that one reason for the variation among feeding trials, besides production steps affecting byproduct quality in winery, the variation among cultivars may have substantial contribution. The main aim of this study was to analyse grape pomace and stems from the area of Slovak Republic and Austria to evaluate their nutritional value for animals.

\section{MATERIAL AND METHODS}

\section{Grape samples}

In total, 54 samples from 3 varieties Zweigelt (ZG) red skinned, Pinot Blanc (PB) white skinned and Green Veltliner $(\mathrm{GV})$ white skinned from 6 different locations (Nitra and Vienna wine region) of Vitis vinifera sp. were analysed. The microclimatic conditions in Nitra wine region (average temperature $10.8{ }^{\circ} \mathrm{C}$, precipitations $988.06 \mathrm{~mm}$ and 95 days in rain) and Vienna wine region (average temperature $12.0^{\circ} \mathrm{C}$, precipitations $716.28 \mathrm{~mm}$ and 74 days in rain) by rp5.ru meteorological server were observed. In each variety the nutritive value was determined for the whole grape (bunch) and by-products of wine industry (pomace, stems). Grape pomace was characterised as a residual skin, seeds and grape pulps after juice pressing in wine industry. Grape stems were only rachis, peduncle and pedicels after removing grape berries.

\section{Chemical analysis}

Standard laboratory techniques were used to determine basic nutrients and fibre contents (AOAC, 2000). Samples were predried under $55 \pm 5{ }^{\circ} \mathrm{C}$ for three days and milled by laboratory mill (Fritsch, GER) to pass $1 \mathrm{~mm}$ sieve. Residual Dry matter (DM) content has been determined gravimetrically at $103 \pm 2{ }^{\circ} \mathrm{C}$. Ash (Ah) was determined by resulting inorganic residue weight after ignition in Muffle furnace at $550 \pm 25^{\circ} \mathrm{C}$, crude protein (CP) as total nitrogen content determined by the Kjeldahl method. Ether extracts (EE) as crude fat was determined by extraction and gravimetric method according to the Soxhlet principle, without previous acid treatment. Starch (ST) was determined polarimetrically after clarification and filtration of the optical rotation of the solution. Then, the difference between the two measurements, multiplied by a known factor, gives the starch content of the sample. Sugars (SG) was determined as extraction of samples in ethanol solution followed by Carrez solution treatment and titration by Luff-Schoorl method. Crude fibre (CF) content was determined gravimetrically as the difference between residue after hydrolysis and after combustion. Neutral detergent fibre (NDF) content was determined in the Ankom 200 Fiber Analyzer (Ankom Technology, U.S.A.) according to procedures derived from Van Soest et al. (1991). Acid detergent fiber (ADF) after hydrolysis in acid detergent soluble of cetaltrimetylamoniumbromide and sulphuric acid determined by Fibertec System 1010 Heat Extractor (Tecator, Switzerland) and Dosi - Fiber (Selecta, Spain). Lignin (ADL) was determined as residue 
after hydrolysis of ADF sample by $72 \%$ solution of sulphuric acid in laboratory temperature. Nitrogen free extracts (NFE), Organic matter (OM), Hemicellulose (H), Cellulose (C) were calculated. Antioxidant activity was determined according to Nishizawa et al. (2005) and Xia et al. (2010), total polyphenols, condensed tannins, and protein precipitation by Kardel et al. (2013).

\section{Statistical analysis of results}

Results were statistically evaluated with IBM SPSS v. 20.0. Descriptive statistics (means, standard deviations, minimum maximum) using One-way ANOVA were generated. Then, statistical significance of nutritional composition between the varieties (3 samples per variety in both countries) within the countries was expressed using Tukey test. For the analysis of relationship between the variables Pearson correlation $(r)$ test was used.

\section{RESULTS}

The total content of DM in the samples of grape bunch $226.08 \pm 18.80 \mathrm{~g} \mathrm{~kg}^{-1}$ in Slovak samples (SK) and 261.44 \pm 30.70 in Austrian samples (AT) was found (Table 1). The highest content was determined in the $\mathrm{PB}(\mathrm{SK})$ and ZG (AT). The concentration of DM in GV $(p<0.01)$ and $Z G(p<0.01)$ compared to PB in SK samples was lower. Then, similar content of OM in both countries was detected. After the comparison of OM concentration in the bunch of $G V, P B$ and $Z G$ the highest $(p<0.01)$ concentrations in the bunch of GV (SK) and ZG (AT) were found. Further, the bunch of GV (SK; p<0.05) and $\mathrm{PB}$ (AT) had the highest content of CP, compared to other cultivars. However, the EE concentrations were the highest in the ZG (SK) and PB (AT) variety $(p<0.01)$. The concentration of CF in SK was also the highest in the ZG bunch but in AT the highest content in $\mathrm{GV}$ bunch was determined. After comparison of $\mathrm{NFE}$, the highest concentration in the $\mathrm{PB}(\mathrm{SK})$ and ZG (AT) bunch variety was determined. However, differences between PB and GV were very slight. Then, the SG content was the highest in the bunch of GV and differences between varieties were between SK samples statistically significant $(p<0.01)$. In AT, samples with the highest content of SG were in the PB variety, differing significantly $(p<0.05)$ compared to GV. ADF was most represented in the bunch of $\mathrm{ZG}(\mathrm{SK})$ and $\mathrm{GV}$ (AT) compared with other cultivars $(\mathrm{p}<0.01)$. Also, in the $Z G$ (SK) and GV (AT) bunch the highest content of NDF was found. In contrast, the PB (SK and AT) variety had the highest content of ADL. Then, the highest amount of $C$ was in the ZG (SK) and GV (AT) bunch and the difference compared to other varieties was large and statistically significant in SK samples $(p<0.01)$. Finally, the concentration of $\mathrm{H}$ was highest in the bunch of $\mathrm{PB}$ (SK) and ZG (AT) variety. Generally, the bunch of grape had the highest content of NFE, OM and SG, but the lowest content of DM, CP, CF, Ah, ST, ADF, NDF, ADL, $\mathrm{C}$ and $\mathrm{H}$ compared to grape stem and pomace.

In comparison with the whole grape bunch and grape pomace, in the grape stem (Table 2) the highest Ah, ST, C and $\mathrm{H}$ content were found. However, the lowest EE and $\mathrm{OM}$ content and consequently the highest content of $\mathrm{DM}$ in the stem of ZG (SK) and PB (AT) variety was detected. Differences in OM were very small with the lowest value in the case of GV (SK) and ZG (AT) stem. Then, the highest

Table 1: Nutrient composition of grape bunch $\left(\mathrm{g}^{\cdot} \cdot \mathrm{kg}^{-1}\right)$

\begin{tabular}{|c|c|c|c|c|c|c|c|c|c|c|c|c|c|c|c|}
\hline & Var & & DM & CP & EE & CF & Ah & NFE & OM & SG & ADF & NDF & L & C & H \\
\hline \multirow[t]{8}{*}{ SK } & GV & $\bar{x}$ & $227.93^{a}$ & $33.46^{a}$ & $11.82^{a}$ & $69.67^{a}$ & $23.65^{a}$ & $861.40^{a}$ & $976.35^{a}$ & $853.86^{a}$ & $102.06^{a}$ & $109.2^{\mathrm{a}}$ & $66.77^{a}$ & $35.29^{a}$ & $7.14^{a}$ \\
\hline & & SD & 0.06 & 1.81 & 0.13 & 1.44 & 0.60 & 2.25 & 0.60 & 3.74 & 3.76 & 0.26 & 2.43 & 6.20 & 3.63 \\
\hline & PB & $\bar{x}$ & $246.80^{b}$ & $29.91^{b}$ & $18.58^{b}$ & $60.07^{b}$ & $26.93^{b}$ & $864.52^{a}$ & $973.07^{b}$ & $832.51^{b}$ & $121.06^{b}$ & $147.49^{a}$ & $87.60^{b}$ & $33.46^{a}$ & $26.43^{b}$ \\
\hline & & SD & 0.20 & 0.93 & 0.14 & 0.69 & 0.40 & 0.59 & 0.40 & 0.71 & 1.62 & 0.79 & 2.28 & 0.81 & 0.93 \\
\hline & $Z G$ & $\bar{x}$ & $203.50^{c}$ & $31.97^{\mathrm{ab}}$ & $26.58^{c}$ & $95.22^{c}$ & $29.71^{c}$ & $816.51^{b}$ & $970.29^{c}$ & $743.35^{c}$ & $151.62^{c}$ & $173.06^{b}$ & $83.41^{b}$ & $68.21^{\mathrm{b}}$ & $21.44^{b}$ \\
\hline & & SD & 0.10 & 0.39 & 1.18 & 0.56 & 0.62 & 0.40 & 0.62 & 6.84 & 2.74 & 0.88 & 0.19 & 2.76 & 3.62 \\
\hline & TA & $\bar{x}$ & 226.08 & 31.78 & 18.99 & 74.99 & 26.76 & 847.48 & 973.24 & 809.91 & 124.92 & 143.25 & 79.26 & 45.65 & 18.33 \\
\hline & & SD & 18.80 & 1.86 & 6.42 & 15.76 & 2.67 & 23.29 & 2.67 & 50.92 & 21.79 & 17.71 & 9.68 & 17.28 & 9.05 \\
\hline \multirow[t]{8}{*}{ AT } & GV & $\bar{x}$ & $238.10^{a}$ & $37.68^{a}$ & $6.29^{a}$ & $67.72^{a}$ & $24.37^{a}$ & $863.94^{a}$ & $975.63^{a}$ & $854.38^{a}$ & $110.27^{a}$ & $115.14^{a}$ & $71.83^{a}$ & $38.44^{a}$ & $4.87^{a}$ \\
\hline & & SD & 2.40 & 0.87 & 0.34 & 2.38 & 0.93 & 3.74 & 0.93 & 3.57 & 0.43 & 1.79 & 2.32 & 2.74 & 1.36 \\
\hline & PB & $\bar{x}$ & $244.13^{a}$ & $38.28^{a}$ & $11.61^{b}$ & $58.86^{b}$ & $28.47^{b}$ & $862.78^{a}$ & $971.53^{b}$ & $865.13^{b}$ & $100.22^{b}$ & $102.98^{a}$ & $71.90^{\mathrm{a}}$ & $28.33^{b}$ & $2.76^{a}$ \\
\hline & & SD & 7.00 & 0.90 & 0.17 & 1.22 & 0.95 & 2.93 & 0.95 & 3.42 & 1.45 & 2.19 & 2.23 & 0.78 & 1.82 \\
\hline & $Z G$ & $\bar{x}$ & $255.03^{a}$ & $30.58^{b}$ & $9.84^{c}$ & $53.34^{c}$ & $24.29^{a}$ & $881.94^{b}$ & $975.71^{a}$ & $857.14^{\mathrm{ab}}$ & $81.09^{c}$ & $96.92^{b}$ & $51.24^{b}$ & $29.85^{b}$ & $15.83^{b}$ \\
\hline & & SD & 5.35 & 1.05 & 0.22 & 1.45 & 0.21 & 1.16 & 0.21 & 1.06 & 1.94 & 2.42 & 1.60 & 0.34 & 0.49 \\
\hline & TA & $\bar{x}$ & 261.44 & 39.24 & 11.56 & 64.29 & 27.29 & 857.62 & 972.71 & 845.21 & 109.88 & 121.68 & 72.50 & 37.38 & 11.80 \\
\hline & & SD & 30.70 & 7.51 & 4.65 & 9.62 & 3.42 & 23.11 & 3.42 & 25.22 & 25.44 & 22.36 & 16.29 & 10.30 & 9.03 \\
\hline
\end{tabular}

Different letters in the columns indicate significant differences. The mean difference is significant at the 0.05 level (Tukey Test). Abbreviations: DM-dry matter, CP-crude proteins, EE-crude fat, CF-crude fibre, Ah-ash, NFE-nitrogen free extracts, OM-organic matter, SG-sugar, ADF-acid detergent fibre, NDF-neutral detergent fibre, L-lignin, C-cellulose, H-hemicelluloses, SK-Slovakia, AT-Austria, GV-Green Veltliner, PB-Pinot Blanc, ZG-Zweigelt, TA-total average, mean, $\overline{\mathrm{x}} \mathrm{SD}$-standard deviation 
amount of CP in GV (SK) and ZG (AT) was observed. However, the difference between $\mathrm{S}$ and $\mathrm{A}$ samples in $\mathrm{CP}$ was relatively high $(\mathrm{p}<0.01)$. Afterwards, the stem of PB $(\mathrm{SK})$ and $\mathrm{ZG}(\mathrm{AT})$ had the highest concentration of EE compared with other cultivars $(\mathrm{p}<0.01)$. Similarly, significant differences $(p<0.01)$ between stems of grape varieties in the CF content were found. The highest CF content was for ZG (SK and AT) and the lowest for GV (SK) and PB (AT) cultivars. ZG (SK) and GV (AT) stem had the highest content of NFE. In the stem of ZG (SK) and GV (AT) no ST was not found. The lowest concentration of SG was in ZG (SK and AT) cultivar, and in comparison with GV and PB lower $(p<0.01)$ content of SG was found. However, in the case of $\mathrm{ADF}$ in the stem of $\mathrm{ZG}(\mathrm{S}$ and $\mathrm{A})$ the highest concentration was determined. Differences between $Z G$ and $\mathrm{GV}$ and $\mathrm{PB}$ were also highly significant $(\mathrm{p}<0.01)$. Moreover, the similar results were in the content of NDF and $\mathrm{L}$ where their highest concentrations in $Z G(S$ and $A$ ) were found. Then, the highest content of $\mathrm{C}$ in GV (SK) and ZG (AT) was observed. The difference in $C$ between samples in both countries was significant $(p<0.05)$. Finally, the lowest quantity of $\mathrm{H}$ in the stem of $\mathrm{PB}(\mathrm{SK})$ and $\mathrm{GV}$ (AT) was determined, with significant differences between varieties.

The nutritive value of grape pomace (Table 3) was represented by the highest concentration of DM, CP, EE,

Table 2: Nutrient composition of grape stem $\left(\mathrm{g} \cdot \mathrm{kg}^{-1}\right)$

\begin{tabular}{|c|c|c|c|c|c|c|c|c|c|c|c|c|c|c|c|c|}
\hline \multicolumn{3}{|c|}{ Variety } & \multirow{2}{*}{$\frac{\text { DM }}{225.67^{a}}$} & \multirow{2}{*}{$\frac{\text { CP }}{85.60^{a}}$} & \multirow{2}{*}{$\frac{\mathrm{EE}}{12.92^{\mathrm{a}}}$} & \multirow{2}{*}{$\frac{\text { CF }}{160.40^{a}}$} & \multirow{2}{*}{$\frac{\text { Ah }}{73.49^{a}}$} & \multirow{2}{*}{$\frac{\text { NFE }}{667.59^{a}}$} & \multirow{2}{*}{$\frac{\text { OM }}{926.51^{a}}$} & \multirow{2}{*}{$\frac{\text { ST }}{53.32^{a}}$} & \multirow{2}{*}{$\frac{\text { SG }}{239.00^{a}}$} & \multirow{2}{*}{$\frac{\text { ADF }}{329.96^{a}}$} & \multirow{2}{*}{$\frac{\text { NDF }}{391.27^{a}}$} & \multirow{2}{*}{$\frac{\mathrm{L}}{158.20^{\mathrm{a}}}$} & \multirow{2}{*}{$\frac{\text { C }}{171.76^{a}}$} & \multirow{2}{*}{$\frac{\mathbf{H}}{61.31^{\mathrm{a}}}$} \\
\hline SK & GV & $\bar{x}$ & & & & & & & & & & & & & & \\
\hline & & SD & 0.06 & 1.63 & 0.16 & 0.43 & 0.31 & 1.74 & 0.31 & 1.14 & 1.31 & 0.20 & 0.19 & 1.98 & 2.17 & 0.34 \\
\hline & PB & $\bar{x}$ & $288.57^{a b}$ & $85.59^{a}$ & $14.30^{b}$ & $171.40^{b}$ & $72.69^{a}$ & $656.01^{b}$ & $927.31^{a}$ & $41.76^{b}$ & $256.78^{b}$ & & $374.49^{a}$ & $158.21^{a}$ & $162.77^{b}$ & \\
\hline & & SD & 0.06 & 1.95 & 0.28 & 0.65 & 2.59 & 0.72 & 2.59 & 1.30 & 1.30 & 1.61 & 0.70 & 0.59 & 2.20 & 2.31 \\
\hline & $Z G$ & $\bar{x}$ & $326.67^{b}$ & $61.83^{b}$ & $11.79^{\circ}$ & $188.54^{c}$ & $67.84^{b}$ & $670.00^{a}$ & $932.16^{b}$ & $0.00^{c}$ & $179.60^{\circ}$ & $387.37^{\circ}$ & $445.30^{b}$ & $237.76^{b}$ & $149.61^{c}$ & $57.94^{\mathrm{ab}}$ \\
\hline & & SD & 57.71 & 0.26 & 0.54 & 2.74 & 1.56 & 3.89 & 1.56 & .00 & 1.27 & 1.01 & 2.74 & 1.03 & 1.70 & 3.28 \\
\hline & TA & $\bar{x}$ & 280.30 & 77.67 & 13.00 & 173.45 & 71.34 & 664.53 & 928.66 & 31.69 & 225.13 & 346.10 & 403.69 & 184.72 & 161.38 & 57.59 \\
\hline & & SD & & & & & & & & & & & & & & \\
\hline \multirow[t]{8}{*}{ AT } & GV & $\bar{x}$ & $223.30^{a}$ & $42.79^{a}$ & $5.37^{a}$ & $168.88^{a}$ & $82.70^{a}$ & $700.26^{a}$ & $917.30^{a}$ & $0.00^{a}$ & $437.57^{a}$ & $270.67^{a}$ & $287.47^{a}$ & $117.41^{a}$ & $153.27^{a}$ & $16.80^{a}$ \\
\hline & & SD & 0.96 & 1.93 & 0.34 & 0.51 & 1.38 & 0.84 & 1.38 & 0.00 & 2.98 & 2.10 & 2.65 & 1.32 & 0.78 & 4.75 \\
\hline & PB & $\bar{x}$ & $271.80^{b}$ & $50.00^{b}$ & $7.35^{b}$ & $166.67^{a}$ & $77.21^{\mathrm{b}}$ & $698.78^{a}$ & $922.79^{b}$ & $25.44^{b}$ & $352.00^{\mathrm{b}}$ & $298.31^{b}$ & $337.95^{b}$ & $141.79^{b}$ & $156.52^{\mathrm{ab}}$ & $39.64^{b}$ \\
\hline & & SD & 22.19 & 1.75 & 0.11 & 2.10 & 1.09 & 4.76 & 1.09 & 1.17 & 2.54 & 2.59 & 1.02 & 2.01 & 4.56 & 3.49 \\
\hline & $Z G$ & $\bar{x}$ & $259.47^{a b}$ & $52.00^{\mathrm{b}}$ & $8.77^{c}$ & $181.78^{b}$ & $84.50^{a}$ & $672.94^{b}$ & $915.50^{\mathrm{a}}$ & $33.38^{c}$ & $324.63^{c}$ & $323.99^{\circ}$ & $378.60^{c}$ & $160.48^{c}$ & $163.51^{c}$ & $54.61^{\mathrm{c}}$ \\
\hline & & SD & 16.05 & 0.35 & 0.42 & 0.67 & 2.07 & 3.30 & 2.07 & 1.75 & 3.04 & 0.42 & 1.03 & 0.66 & 0.24 & 0.61 \\
\hline & TA & $\bar{x}$ & 262.61 & 54.37 & 7.52 & 169.65 & 78.87 & 689.60 & 921.13 & & & 303.00 & & & & 38.49 \\
\hline & & SD & 30.95 & 11.67 & 1.44 & 8.00 & 5.65 & 11.83 & 5.65 & 13.29 & 43.75 & 21.99 & 9.23 & 17.70 & 4.89 & 14.57 \\
\hline
\end{tabular}

Different letters in the columns indicate significant differences. The mean difference is significant at the 0.05 level (Tukey Test). Abbreviations: DM-dry matter, CP-crude proteins, EE-crude fat, CF-crude fibre, Ah-ash, NFE-nitrogen free extracts, OM-organic matter, ST-starch, SG-sugar, ADF-acid detergent fibre, NDF-neutral detergent fibre, L-lignin, C-cellulose, H-hemicelluloses, SK-Slovakia, AT-Austria, GV-Green Veltliner, PB-Pinot Blanc, ZG-Zweigelt, TA-total average, $\bar{x}$ mean, SD-standard deviation

Table 3: Nutrient composition of grape pomace $\left(\mathrm{g} \cdot \mathrm{kg}^{-1}\right)$

\begin{tabular}{|c|c|c|c|c|c|c|c|c|c|c|c|c|c|c|c|c|}
\hline \multicolumn{3}{|c|}{ Variety } & \multirow{2}{*}{$\frac{\mathrm{DM}}{353.57^{\mathrm{a}}}$} & \multirow{2}{*}{$\frac{\text { CP }}{100.43^{a}}$} & \multirow{2}{*}{$\frac{\mathrm{EE}}{50.38^{\mathrm{a}}}$} & \multirow{2}{*}{$\frac{\text { CF }}{157.81^{a}}$} & \multirow{2}{*}{$\frac{\text { Ah }}{49.80^{a}}$} & \multirow{2}{*}{$\frac{\text { NFE }}{641.57^{a}}$} & \multirow{2}{*}{$\frac{\text { OM }}{950.20^{a}}$} & \multirow{2}{*}{$\frac{\text { ST }}{20.56^{a}}$} & \multirow{2}{*}{$\frac{\text { SG }}{341.38^{a}}$} & \multirow{2}{*}{$\frac{\text { ADF }}{269.76^{a}}$} & \multirow{2}{*}{$\frac{\text { NDF }}{276.61^{a}}$} & \multirow{2}{*}{$\frac{\mathrm{L}}{182.03^{\mathrm{a}}}$} & \multirow{2}{*}{$\frac{\text { C }}{87.73^{a}}$} & \multirow{2}{*}{$\frac{\mathbf{H}}{6.85^{\mathrm{a}}}$} \\
\hline SK & GV & $\bar{x}$ & & & & & & & & & & & & & & \\
\hline & & SD & 0.15 & 0.29 & 0.58 & 1.19 & 1.89 & 3.30 & 1.89 & & 3.33 & 2.50 & 0.52 & 0.70 & 1.80 & 1.99 \\
\hline & PB & $\bar{x}$ & $370.97^{b}$ & $105.44^{b}$ & $82.86^{b}$ & & & $587.44^{b}$ & & $41.87^{b}$ & & $347.75^{b}$ & & & & $36.21^{b}$ \\
\hline & & SD & 0.06 & .21 & 1.15 & 19 & 0.24 & 60 & 0 & .80 & 28 & 2.71 & 2.00 & 3.09 & .05 & 5.30 \\
\hline & $Z G$ & $\bar{x}$ & $393.70^{c}$ & $109.78^{c}$ & $100.87^{c}$ & $233.26^{c}$ & $60.45^{c}$ & $54^{c}$ & & $0.00^{c}$ & $4.73^{c}$ & $440.73^{c}$ & $55^{c}$ & $34^{c}$ & $39^{\circ}$ & $88.82^{c}$ \\
\hline & & SD & & & & & & & & & & & & & & \\
\hline & TA & $\bar{x}$ & 372.74 & 105.22 & 78.04 & 190.68 & 51.18 & 574. & 8.82 & 20.81 & 185.67 & 352.75 & 71 & & 39 & 43.96 \\
\hline & & SD & .43 & & 22.1 & & & & & 14 & & & & & & 36.09 \\
\hline \multirow[t]{8}{*}{ AT } & GV & $\bar{x}$ & $327.00^{a}$ & 73 & $30.59^{a}$ & $120.07^{a}$ & $45.50^{a}$ & 730. & & $0.00^{\mathrm{a}}$ & 542. & & $34^{a}$ & & 77. & $11.29^{\mathrm{ac}}$ \\
\hline & & SD & 2.79 & 0.67 & 0.17 & 2.93 & 1.33 & 4.81 & 1.33 & 0.00 & 3.39 & 2.53 & 0.84 & 2.1 & & 1.68 \\
\hline & PB & $\bar{x}$ & $360.60^{b}$ & $89.45^{b}$ & $47.61^{b}$ & $171.04^{b}$ & $46.45^{a}$ & $645.45^{b}$ & $953.55^{a}$ & $0.00^{a}$ & $415.32^{b}$ & $292.90^{\mathrm{b}}$ & $335.52^{b}$ & $184.14^{b}$ & $108.76^{b}$ & $42.62^{b}$ \\
\hline & & SD & & & & & & & & & & & & & & 1.33 \\
\hline & ZG & $\bar{x}$ & & & $64.57^{c}$ & & $70.7 s$ & 487. & & $0.00^{\mathrm{a}}$ & 12.45 & & & & & \\
\hline & & SD & & & & & & & & & & 2.09 & 1.30 & & & 3.38 \\
\hline & TA & $\bar{x}$ & 356.00 & 104.84 & 53.92 & 206.37 & 56.03 & 578.84 & 943.97 & 0.00 & 250.58 & 322.42 & 342.50 & 198.10 & 124.32 & 20.08 \\
\hline & & SD & 21.93 & 25.44 & 17.02 & 68.05 & 11.12 & 119.14 & 11.12 & 0.00 & 242.91 & 82.46 & 86.42 & 48.63 & 35.06 & 14.04 \\
\hline
\end{tabular}

Different letters in the columns indicate significant differences. The mean difference is significant at the 0.05 level (Tukey Test). Abbreviations: DM-dry matter, CP-crude proteins, EE-crude fat, CF-crude fibre, Ah-ash, NFE-nitrogen free extracts, OM-organic matter, ST-starch, SG-sugar, ADF-acid detergent fibre, NDF-neutral detergent fibre, L-lignin, C-cellulose, H-hemicelluloses, SK-Slovakia, AT-Austria, GV-Green Veltliner, PB-Pinot Blanc, ZG-Zweigelt, TA-total average, $\overline{\mathrm{X}}$-mean, SD-standard deviation 
CF, ADF, NDF and L compared to grape bunch and stem. However, the content of NFE and SG in comparison with the grape stems and whole bunches was the lowest. The highest content of DM in ZG (SK and AT) pomace was found. Moreover, the differences between PB pomace and GV pomace were significant $(p<0.01)$ for all above mentioned analyses?. Furthermore, in ZG pomace (SK and $A T$ ) the highest amount of $C P$ was found. The $C P$ concentration in $\mathrm{PB}$ and $\mathrm{GV}$ pomace compared to $\mathrm{ZG}$ pomace was lower $(p<0.01)$. The amount of $E E$ was lower in GV compared with PB and ZG pomace in both countries. Moreover, the lowest content of CF in GV (SK and $A T)$ was also determined $(\mathrm{p}<0.01)$ compared to $\mathrm{PB}$ and ZG pomace. NFE concentrations were the highest in GV pomace $(p<0.01)$ in comparison with PB and ZG in both countries. The highest concentrations of $\mathrm{ST}$ in $\mathrm{PB}$ pomace were determined. However, in the case of ZG pomace in SK and all varieties in AT no ST content was found. Large differences between SG concentrations in pomace were observed. Thus, GV pomace had the highest content of SG, then PB pomace $(\mathrm{p}<0.01)$ and finally $Z G$ pomace $(p<0.01)$ in both countries. The highest concentrations of ADF, NDF, L, C and H in ZG pomace in both countries were found, except of $\mathrm{H}$ in AT samples where the highest concentrations in $\mathrm{PB}$ pomace were detected.

Fig. 2 shows the comparison of nutritive value of grape bunch and wine by-products per $\mathrm{kg} \mathrm{OM}$. Thus, grape pomace had the lowest $(\mathrm{p}<0.01)$ ratio of NFE $(\mathrm{SK} 60.56 \%$; AT $65.57 \%$ ), probably because of lower content of SG which gets lost during the grape pressing during wine production. Afterwards, the whole bunch had the highest $(\mathrm{p}<0.01)$ ratio of NFE (SK 87.07\%; AT 89.25\%) but the lowest ratio of CF (SK 7.71\%; AT 6.16\%) and CP (SK $3.27 \%$; AT 3.65\%) $(\mathrm{p}<0.01)$. On the other side, grape pomace had significantly $(\mathrm{p}<0.01)$ the highest ratio of CP (SK 11.09\%; AT 10.38\%), EE (SK 8.23\%; AT 5.05\%) and CF (SK 20.12\%; AT 19.00\%). Then, the grape stem was characterised with balanced ratio of CP (SK 8.37\%; ATT 5.25\%), CF (SK 18.67\%; AT 18.78\%) and NFE (SK $71.56 \%$; AT $75.19 \%$ ), but there is slight content of EE (SK $1.40 \%$, AT $0.78 \%$ ).

Fig. 3 shows fibre fractions recalculated per $\mathrm{kg}$ of NDF. From this point of view, on the one hand, grape pomace in SK had the highest $(\mathrm{p}<0.01) \mathrm{L}$ proportion $(61.66 \%)$, but the lowest $(\mathrm{p}<0.01)$ ratio of $\mathrm{C}(28.78 \%)$ and $\mathrm{H}$ $(9.56 \%)$. On the other hand, grape stem had the lowest L $(45.36 \% ; \mathrm{p}<0.01)$ proportion. However, the grape stem had the highest $(\mathrm{p}<0.01)$ proportion of $\mathrm{C}(40.32 \%)$ and $\mathrm{H}(14.32 \%)$. In AT, the highest proportion of L (61.69\%) and the lowest proportion of $\mathrm{C}(30.56 \%)$ was found in grape bunch. Similarly, the lowest H proportion $(7.42 \%)$ was determined in the grape pomace. The same results

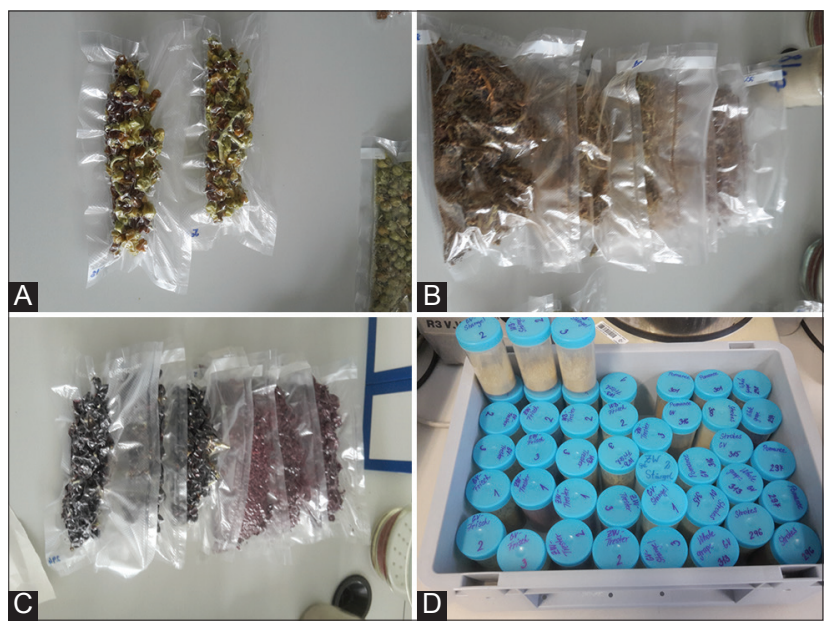

Fig 1. Grape bunch (A), stem (B), pomace (C) and laboratory samples (D) of grape by-products before analysisd.

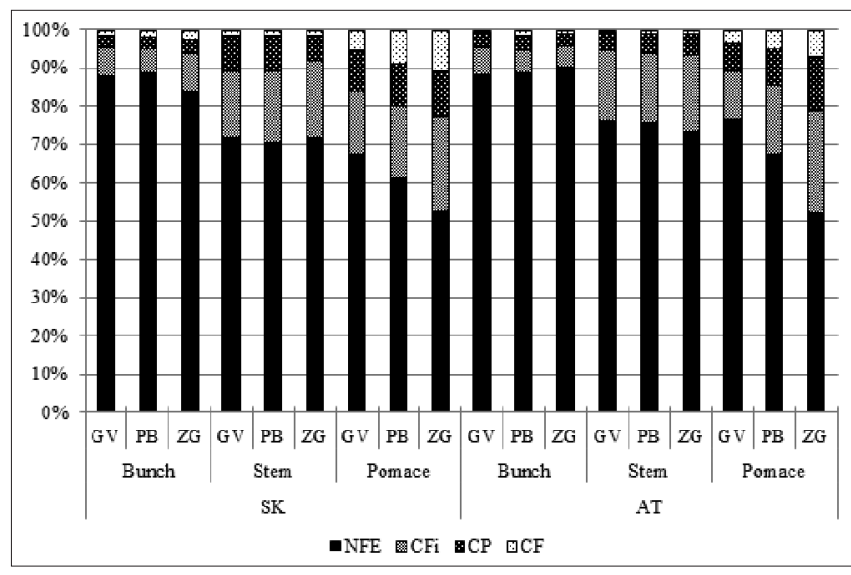

Fig 2. Chemical composition per kg OM. GV - Green Veltliner, PB - Pinot Blanc, ZG - Zweigelt, SK - Slovakia, AT - Austria, NFE - nitrogen free extract, CF - crude fibre, CP - crude proteins, EE - crude fat.

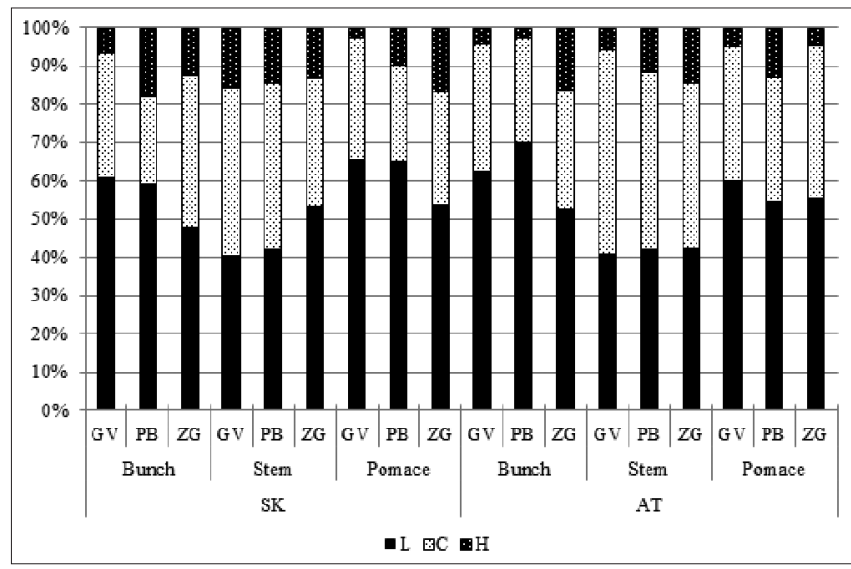

Fig 3. Proportion of fibre components per kg NDF. GV - Green Veltiner, PB - Pinot Blanc, ZG - Zweigelt, SK - Slovakia, AT - Austria, L - lignin, $\mathrm{C}$ - cellulose, $\mathrm{H}$ - hemicellulose.

in comparison with SK samples were found, thus in the grape stem the highest concentrations of $\mathrm{C}(47.61 \%)$ and $\mathrm{H}(10.67 \%)$ were observed. 
Higher antioxidant activity (Table 4) in grape stem in both countries in comparison with whole bunch $(\mathrm{p}<0.01)$ and pomace $(p<0.01)$ was determined for ABTS. However, DPPH method did not show significant results between grape by-products in antioxidant activity in SK samples.

For protein precipitation, grape stem had lower values in both countries compared to bunch $(\mathrm{p}<0.01)$ and grape pomace $(p<0.01)$. In contrast, in grape stem higher content of total phenols in comparison with grape bunch $(\mathrm{p}<0.01)$ and pomace $(\mathrm{p}<0.01)$ in SK and AT samples was detected. The content of condensed tannins between byproducts was almost the same. In grape pomace (Table 5), higher content of $\mathrm{C}$ led to higher concentration of CT (SK, $r=1.00, \mathrm{p}<0.01$; AT, $r=0.911, \mathrm{p}>0.05)$ and DPPH $(\mathrm{SK}, r=0.941, \mathrm{p}>0.05$; AT, $r=0.996, \mathrm{p}<0.05)$. In grape stem, concentrations of $\mathrm{L}$ are correlated to DPPH antioxidant activity (SK, $r=0.994, \mathrm{p}<0.05$; AT, $r=0.791, \mathrm{p}>0.05$ ) and CT content (SK, $r=0.998, \mathrm{p}<0.05$; AT, $r=0.934$, $\mathrm{p}>0.05$ ). Content of TP in SK samples were strongly correlated to H content $(r=0.988 ; \mathrm{p}<0.05)$.

\section{DISCUSSION}

Nutritive value of wine by-products depends on the technical processing of wine production and may also exist differences caused by grape origin (Baumgärtel et al., 2007). According to several researches, the DM and OM content in grape pomace varied from 273 to $408 \mathrm{~g} \mathrm{~kg}^{-1}$ and 933 to $943 \mathrm{~g} \cdot \mathrm{kg}^{-1}$ respectively (Baumgärtel et al., 2007; González-Centeno, 2010; Azevêdo et al., 2012), which was confirmed in the present study. In contrary, the content of CP in the grape pomace varied from 77 to $175 \mathrm{~g} \mathrm{~kg}^{-1}$ (Peiretti et al., 2017; Russo et al., 2017). In comparison with our analysis was CP content in their found interval. After comparison of EE concentration with Azevêdo et al. (2012) $74 \mathrm{~g} \mathrm{~kg}^{-1}$, Zalikarenab et al. (2007) and Molina et al. (2008) $50-71 \mathrm{~g} \mathrm{~kg}^{-1}$ in grape pomace higher or lower EE values except of GV (SK) and ZG (AT) variety were determined. In contrary, CF content in grape pomace compared to Baumgärtel et al. (2007) was

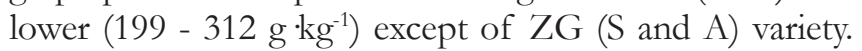
Then, the content of Ah $62-79 \mathrm{~g} \mathrm{~kg}^{-1}$ in experiments

Table 4: Antioxidant activity, total phenols content, condensed tannins content and protein precipitation of grape by-products

\begin{tabular}{|c|c|c|c|c|c|c|c|c|c|c|c|}
\hline & & \multicolumn{2}{|c|}{ ABTS $\left(\mu \mathrm{mol} \cdot \mathrm{g}^{-1}\right)$} & \multicolumn{2}{|c|}{ DPPH $\left(\mu \mathrm{mol} \cdot \mathrm{g}^{-1}\right)$} & \multicolumn{2}{|c|}{ TP gGAE-100 $\mathrm{g}^{-1}$} & \multicolumn{2}{|c|}{ CT $g \cdot 100 g^{-1}$} & \multicolumn{2}{|c|}{ PP $\mathrm{mg} \cdot \mathrm{CT}^{-1}$} \\
\hline & & $\overline{\mathbf{x}}$ & SD & $\overline{\mathbf{x}}$ & SD & $\overline{\mathbf{x}}$ & SD & $\overline{\mathbf{x}}$ & SD & $\overline{\mathbf{x}}$ & SD \\
\hline \multirow{3}{*}{ SK } & Bunch & $289.00^{\mathrm{a}}$ & 103.96 & 265.90 & 100.14 & $2.46^{a}$ & 0.95 & 1.20 & 0.43 & $4.53^{a}$ & 1.00 \\
\hline & Pomace & $946.00^{\mathrm{b}}$ & 244.60 & 441.18 & 166.58 & $6.33^{b}$ & 1.32 & 1.29 & 1.30 & $2.77^{\mathrm{ab}}$ & 0.64 \\
\hline & Stem & $1094.85^{b}$ & 98.03 & 525.15 & 197.61 & $6.70^{b}$ & 0.60 & 1.30 & 1.10 & $1.99^{b}$ & 0.29 \\
\hline \multirow{3}{*}{ AT } & Bunch & $271.16^{a}$ & 64.35 & $277.85^{\mathrm{a}}$ & 36.54 & $1.56^{\mathrm{a}}$ & 0.34 & 1.14 & 0.26 & $4.95^{\mathrm{a}}$ & 0.63 \\
\hline & Pomace & $720.62^{b}$ & 129.65 & $563.70^{b}$ & 69.21 & $4.09^{b}$ & 0.99 & 1.79 & 1.23 & $2.21^{b}$ & 0.09 \\
\hline & Stem & $979.49^{b}$ & 169.14 & $770.85^{c}$ & 111.95 & $5.92^{c}$ & 0.63 & 2.27 & 1.40 & $1.88^{b}$ & 0.35 \\
\hline
\end{tabular}

Different letters in the columns indicate significant differences. The mean difference is significant at the 0.05 level (Tukey Test). Abbreviations: ABTS-antioxidant activity according to ABTS method, DPPH-antioxidant activity according to DPPH method, TP-total phenols, CT-condensed tannins, PP-protein precipitation, SK-Slovakia, AT-Austria

Table 5: Relationships between fibre fractions and ABTS, DPPH, TP, CT and PP in grape pomace (bold numbers) and stem (italic numbers)

\begin{tabular}{|c|c|c|c|c|c|c|c|c|c|}
\hline & & ABTS & DPPH & TP & CT & PP & $\mathbf{L}$ & C & H \\
\hline \multirow[t]{8}{*}{ SK } & ABTS & & 0.582 & 0.908 & 0.242 & -0.153 & 0.757 & 0.272 & 0.487 \\
\hline & DPPH & 0.530 & & 0.869 & 0.930 & 0.715 & 0.972 & 0.941 & $0.994^{*}$ \\
\hline & $\mathrm{TP}$ & 0.977 & 0.337 & & 0.626 & 0.275 & 0.961 & 0.650 & 0.808 \\
\hline & $\mathrm{CT}$ & 0.490 & $0.999^{*}$ & 0.293 & & 0.922 & 0.817 & $1.000^{* *}$ & 0.965 \\
\hline & PP & -0.332 & 0.624 & -0.525 & 0.660 & & 0.530 & 0.910 & 0.789 \\
\hline & $\mathrm{L}$ & 0.432 & $0.994^{*}$ & 0.231 & $0.998^{*}$ & 0.707 & & 0.834 & 0.939 \\
\hline & C & -0.031 & -0.864 & 0.182 & -0.887 & -0.932 & -0.915 & & 0.973 \\
\hline & $\mathrm{H}$ & 0.933 & 0.189 & $0.988^{*}$ & 0.143 & -0.650 & 0.078 & 0.331 & \\
\hline \multirow[t]{8}{*}{ AT } & ABTS & & 0.805 & $0.991^{*}$ & 0.410 & -0.801 & 0.557 & 0.750 & -0.598 \\
\hline & DPPH & 0.884 & & 0.719 & 0.871 & -0.290 & 0.941 & $0.996^{*}$ & -0.006 \\
\hline & $\mathrm{TP}$ & 0.952 & 0.698 & & 0.285 & -0.874 & 0.442 & 0.654 & -0.700 \\
\hline & $\mathrm{CT}$ & 0.058 & 0.519 & -0.251 & & 0.217 & 0.986 & 0.911 & 0.485 \\
\hline & PP & -0.959 & -0.980 & -0.826 & -0.339 & & 0.050 & -0.204 & 0.959 \\
\hline & $\mathrm{L}$ & 0.412 & 0.791 & 0.113 & 0.934 & -0.654 & & 0.967 & 0.332 \\
\hline & C & 0.651 & 0.930 & 0.387 & 0.796 & -0.840 & 0.960 & & 0.082 \\
\hline & $\mathrm{H}$ & 0.372 & 0.763 & 0.070 & 0.948 & -0.620 & $0.999^{*}$ & 0.947 & \\
\hline
\end{tabular}

ABTS-antioxidant activity according to ABTS method, DPPH-antioxidant activity according to DPPH method, TP-total phenols, CT-condensed tannins, PPprotein precipitation, L-lignin, C-cellulose, H-hemicelluloses, SK-Slovakia, AT-Austria. Statistically significant relationship are marked with * $(p<0.05)$ and ${ }_{* *}(p<0.01)$ 
of Zalikarenab et al. (2007) and Molina et al. (2008) was higher in comparison with our findings except of ZG (AT) variety. Corbin et al. (2015) found the content of ST in the grape marc on the similar level from 27 to $40 \mathrm{~g} \mathrm{~kg}^{-1}$ like in SK samples, but the concentrations of NFE compared to our results were generally lower $\left(314 \mathrm{~g} \mathrm{~kg}^{-1}-539 \mathrm{~g} \mathrm{~kg}^{-1}\right)$, except of $Z G$ variety in both countries. In the case of SG concentrations, variety of ZG had lower content compared to their findings $\left(148-430 \mathrm{~g} \mathrm{~kg}^{-1}\right)$, however SG content in another two varieties from Slovakia was in their mentioned interval but lower in comparison with GV variety from Austria. Then, Russo et al. (2017) reported in grape pomace similar content of NDF 215 - $614 \mathrm{~g} \mathrm{~kg}^{-1}$ and ADF 173 - $561 \mathrm{~g} \mathrm{~kg}^{-1}$, but their found intervals of $\mathrm{NDF}$ and ADF contents were compared to varieties in our research. In the GV (SK and AT) and PB (AT) variety lower concentrations of $\mathrm{L}$ in comparison with Baumgärtel et al. (2007) (202 to $267 \mathrm{~g} \mathrm{~kg}^{-1}$ ) were found. However, in another two varieties the content of $\mathrm{L}$ was in their found interval. The content of $\mathrm{C}$ in comparison with the research of Zalikarenab et al. (2007) $\left(80-90 \mathrm{~g} \mathrm{~kg}^{-1}\right)$ and Molina et al. (2008) $\left(110 \mathrm{~g} \mathrm{~kg}^{-1}\right)$ was similar, but the higher concentrations of $\mathrm{C}$ in the $\mathrm{ZG}$ variety in both countries were found. On the other side, lower content of $\mathrm{H}$ in the GV (S and $\mathrm{A}$ ) and ZG (AT) variety in comparison with Zalikarenab et al. (2007) (31 - $\left.54 \mathrm{~g} \mathrm{~kg}^{-1}\right)$ and Molina et al. (2008) $\left(89 \mathrm{~g} \mathrm{~kg}^{-1}\right)$, but another varieties had $\mathrm{H}$ content at the similar level.

The nutrient composition of grape stem for use as animal feed was not well examined in literature up to now. Basalan et al. (2011) found in the grape stalk similar content of $\mathrm{DM}\left(314 \mathrm{~g} \mathrm{~kg}^{-1}\right)$ in comparison with ZG (SK) variety, but it was higher compared to ZG (AT), GV and PB variety. Similar results in the comparison with Spigno et al. (2013) in the case of CP in grape stalks were found, where the concentrations of CP from 37 to $97 \mathrm{~g} \mathrm{~kg}^{-1}$ were examined. Then, the EE content in the comparison with Basalan et al. (2011) $12.2 \mathrm{~g} \mathrm{~kg}^{-1}$ was the same and in the interval of Spigno et al. (2013) from 3 to $21 \mathrm{~g} \mathrm{~kg}^{-1}$. Afterwards, the contents of Ah from SK samples were in the interval of reported findings of Peiretti et al. (2017) and Basalan et al. (2011) from 53.6 to $76.4 \mathrm{~g} \mathrm{~kg}^{-1}$ but lower in comparison with AT samples. Similarly, Basalan et al. (2011) determined the ADF and NDF content in grape stem $324 \mathrm{~g} \mathrm{~kg}^{-1}$ and $433 \mathrm{~g} \mathrm{~kg}^{-1}$, that is close to the concentrations in the $\mathrm{PB}(\mathrm{SK}), \mathrm{GV}(\mathrm{SK})$ and $\mathrm{ZG}(\mathrm{AT})$ variety in the case of ADF and like the ZG (SK) variety in the case of NDF. Furthermore, Spigno et al. (2013) determined L, C and H content in the grape stalks where L content was from 173 to $263 \mathrm{~g} \mathrm{~kg}^{-1}$. Compared to their findings in the all varieties except of ZG (SK) lower content of $\mathrm{L}$ was found. Then, in their research the content of C from 171 to $241 \mathrm{~g} \mathrm{~kg}^{-1}$ was determined. Similarly, all varieties had lower content of $C$ except of GV (SK) in comparison with their findings.
However, the content of $\mathrm{H}$ from 43 to $64 \mathrm{~g} \mathrm{~kg}^{-1}$ was similar in all examined varieties except of GV (AT) and PB (AT).

The main classes of phenols presented in red and white grapevine are hydroxycinnamic tartaric acids, hydroxybenzoic acids, flavonols, flavonols, anthocyanins and stilbenoids (Giuffrè, 2013; Reščič et al., 2016). In the case of total phenols content, higher concentrations of TP in comparison with Ky et al. (2014) $(1.90-4.05 \mathrm{~g}$ GAE $\left.\cdot 100 \mathrm{~g}^{-1}\right)$ and Baumgärtel et al. (2007) $(5,1-5,9 \mathrm{~g}$ GAE $\left.\cdot 100 \mathrm{~g}^{-1}\right)$ were found, except of samples of grape pomace in SK samples. In the research of Rockenbach et al. (2011) was content of TP similar (3.26 - $\left.7.47 \mathrm{~g} \mathrm{GAE} \cdot 100 \mathrm{~g}^{-1}\right)$ compared to our results except of AT bunch. For another comparison, in grape seeds the similar content of TP from

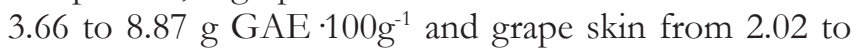
$5.23 \mathrm{~g} \mathrm{GAE} \cdot 100 \mathrm{~g}^{-1}$ were found (Baumgärtel et al., 2007). Furthermore, in grape stem the concentration of TP in the interval of Gonzáles-Centeno et al. (2012) was from 4.7 to $11.52 \mathrm{~g} \cdot 100 \mathrm{~g}^{-1}$. Llober and Cañellas (2007) found that TP content in grape stem is higher in comparison with grape pomace. In the case of antioxidant activity ABTS and DPPH, compared to Rockenbach et al. (2011), higher ABTS (193.36 - $\left.485.42 \mu \mathrm{mol} \mathrm{g}^{-1}\right)$ and DPPH (188.02 - 505.52 $\left.\mu \mathrm{mol} \mathrm{g}^{-1}\right)$ activity in grape pomace in our results was found. After comparison of ABTS (590 - $940 \mu \mathrm{mol} \mathrm{g}^{-1}$ ) with Garau et al. (2015) higher grape stem antioxidant activity in our research was found. However, DPPH activity was in their found interval except of A samples (480 - $\left.610 \mu \mathrm{mol} \mathrm{g}^{-1}\right)$. Also, Ivanišová et al. (2018) found high antioxidant acitivity in grape samples with high content of TP. Then, CT content in grape pomace was lower in comparison with González-Centeno et al. (2013) (5.08 - $\left.9.21 \mathrm{~g} \cdot 100 \mathrm{~g}^{-1}\right)$ and also lower in grape stem in comparison with González-Centeno et al. (2012) (7.91 - $\left.12.49 \mathrm{~g} \cdot 100 \mathrm{~g}^{-1}\right)$.

The high values of linear correlation coefficients indicate that the phenolics were indeed the major contributor of the antioxidant activity (Candrawinata et al., 2014). Then, Aldred et al. (2009) said that tannins are in direct interaction with cellulose ant plant cell walls like lignin. NFE admixtures can decrease antioxidant activity owing to the possibility of hydrogen bonding of their polar groups with lignin phenolic groups (Dizhibite et al., 2004). According to results of Zarei and Shawrang (2016) negative correlation between ADF, NDF and CT in pomegranate seed were found. Furthermore, Garau et al. (2015) found similar relationship between ABTS, DPPH and TP, CT, where higher antioxidant activity was in strong relationship with TP and CT content.

\section{CONCLUSION}

By-products from the winery production have average nutritional value because of higher content of lignin that 
could be limiting factor for the digestibility. Generally, there are differences between the locations and cultivars. However, the results show that the grape pomace had high ratio of $\mathrm{CP}, \mathrm{EE}$ and $\mathrm{CF}$ with the still solid concentrations of $\mathrm{S}$ except of variety from red grape. Also, the grape pomace is source of $\mathrm{L}$, but there is low ratio of $\mathrm{C}$ and $\mathrm{H}$. The grape stem is characterised with balanced content of $\mathrm{CP}, \mathrm{CF}$ and NFE with residual S after grape pressing, but there is low concentration of EE. Also, grape stem has high concentration of $\mathrm{H}$ and $\mathrm{C}$. The highest antioxidant activity, content of total phenols and condensed tannins are in the grape stem. However, the highest protein precipitation is in grape pomace. Then, higher content of $\mathrm{C}$ leads to statistically significant higher concentration of CT in grape pomace. Moreover, in grape stem, higher concentrations of L lead to higher DPPH antioxidant activity and CT content. Afterwards, content of TP is in strong relationship with $\mathrm{H}$ content. Finally, similar tendencies are in nutritional content, antioxidant activity, $\mathrm{CT}$ and TP of wine by-products in the case of comparison between Slovakia and Austria.

\section{ACKNOWLEDGEMENTS}

This work was supported by the Slovak Research and Development Agency under the contract no. APVV-160170 (By-products from grape processing as an bioactive substances source in animal nutrition). We thank the team of the Institute of Animal Nutrition, Livestock Products and Nutrition Physiology (TTE), University of Natural Resources and Live Sciences (BOKU), Vienna/AT for performing the analyses of antioxidant activity, total polyphenols, condensed tannins, and protein precipitation.

\section{Authors' contribution}

O. H.: author of the article, G. B.: overall planning of Slovak part of research, D. B.: revision and critical revision, M. Š.: data analysis, M. J.: preparation of samples in Slovak part of research, M. R.: laboratory analysis in Slovak part of research, L. Z.: laboratory data collection, R. P. and C. P.: laboratory analysis in Austria part of research, J. A. S.: preparation of samples in Austria part of research, M. G.: overall planning of Austria part of research

\section{REFERENCES}

Abarghuei, M. J., Y. Rouzbehan and D. Alipour. 2010. The influence of the grape pomace on the ruminal parameters of sheep. Livest. Sci. 132: 73-79.

Aldred, E. M., C. H. Buck and K. Vall. 2009. Phenols. In: Pharmacology: A Handbook for Complementary Healthcare Professionals. Elsevier Health Sciences, United Kingdom, pp. 149-166.

Álvarez-Casas, M., C. García-Jares, M. Llompart and M. Lores. 2014. Effect of experimental parameters in the pressurized solvent extraction of polyphenolic compounds from white grape marc. Food Chem. 157: 524-532.

Azevêdo, J. A. G., S. C. Valadares Filho, D. S. Pina, E. Detmann, L. G. R. Pereira, R. F. D. Valadares and P. B. Benedeti. 2012. Nutritional diversity of agricultural and agro-industrial byproducts for ruminant feeding. Arq. Bras. Med. Vet. Zootec. 64: 1246-1255.

Basalan, M., T. Gungor, F. N. Owens and I. Yalcinkaya. 2011. Nutrient content and in vitro digestibility of Turkish grape pomaces. Anim. Feed Sci. Tech. 169: 194-198.

Baumgärtel, T., H. Kluth, K. Epperlein and M. Rodehutscord. 2007. A note on digestibility and energy value for sheep of different grape pomace. Small Rumin. Res. 67: 302-306.

Belibasakis, N. G., E. Progia, A. Papaioannou and G. Skulidis. 1996. Effects of ensiled wet grape marc on milk production. Milk composition and blood components in dairy cows. Zivocisna Vyroba-UZPI (Czech Republic). 41: 307-310.

Brenes, A., A. Viveros, I. Goni, C. Centeno, S. G. Sayago-Ayerdy, I. Arija and F. Saura-Calixto. 2008. Effect of grape pomace concentrate and vitamin $\mathrm{E}$ on digestibility of polyphenols and antioxidant activity in chickens. Poult. Sci. 87: 307-316.

Brenes, A., A. Viveros, S. Chamorro and I. Arija. 2016. Use of polyphenol-rich grape by-products in monogastric nutrition. A review. Anim. Feed Sci. Tech. 211: 1-17.

Candrawinata, V. I., J. B. Golding, P. D. Roach and C. E. Stathopoulos. 2014. Optimisation of the phenolic content and antioxidant activity of apple pomace aqueous extracts. CyTA-J. Food. 13: 293-299.

Corbin, K. R., Y. S. Y. Hsieh, N. S. Betts, C. S. Byrt, M. Henderson, J. Stork and R. A. Burton. 2015. Grape marc as a source of carbohydrates for bioethanol: Chemical composition, pretreatment and saccharification. Bioresour. Technol. 193: 76-83.

Dizhbite, T., G. Telysheva, V. Jurkjane and U. Viesturs. 2004. Characterization of the radical scavenging activity of ligninsnatural antioxidants. Bioresour. Technol. 95: 309-317.

Domínguez, J., H. Martínez-Cordeiro and M. Lores. 2016. Earthworms and grape marc: Simultaneous production of a high-quality biofertilizer and bioactive-rich seeds. In: Grape and Wine Biotechnology. InTech, Rijeka, Croatia.

Nistor, E., A. Dobrei, A. Dobrei, V. Bampidis and V. Ciolac. 2014. Grape pomace in sheep and dairy cows feeding. J. Hortic. For. Biotech. 18: 146-150.

Ferreira, W. M., M. J. Fraga and R. Carabañco. 1996. Inclusion of grape pomace, in substitution for alfalfa hay, in diets for growing rabbits. Anim. Sci. 63: 167-174.

Fiesel, A., D. K. Gessner, E. Most and K. Eder. 2014. Effects of dietary polyphenol-rich plant products from grape or hop on pro-inflammatory gene expression in the intestine, nutrient digestibility and faecal microbiota of weaned pigs. BMC Vet. Res. 10: 196.

Fontana, A. R., A. Antoniolli and R. Bottini. 2013. Grape pomace as a sustainable source of bioactive compounds: Extraction, characterization, and biotechnological applications of phenolics. J. Agric. Food Chem. 61: 8987-9003.

Garau, M. C., M. R. González-Centeno, J. M. Luna, A. Negre, C. Rosselló and A. Femenia. 2015. Potential of landrace winery by-products (Vitis vinifera L.) as a source of phenolic compounds with antioxidant properties. OENO One. 49: 241-251.

Guerra-Rivas, C., B. Gallardo, Á. R. Mantecón, M. del Álamo-Sanza and T. Manso. 2016. Evaluation of grape pomace from red wine by-product as feed for sheep. J. Sci. Food Agric. 97: 1885-1893.

Giuffrè, A. M., S. Tellah, M. Capocasale, C. Zappia, M. Latati, 
M. Badiani and S. M. Ounane. 2016. Seed oil from ten Algerian peanut landraces for edible use and biodiesel production. J. Oleo Sci. 65: 9-20.

Giuffrè, A. M., C. Zappia and M. Capocasale. 2017a. Effects of high temperatures and duration of heating on olive oil properties for food use and biodiesel production. J. Am. Oil Chem. Soc. 94: 819-830.

Giuffrè, A. M., M. Capocasale, C. Zappia and M. Poiana. 2017b. Influence of high temperature and duration of heating on the sunflower seed oil properties for food use and bio-diesel production. J. Oleo Sci. 66: 1193-1205.

Giuffrè, A. M. 2013. HPLC-DAD detection of changes in phenol content of red berry skins during grape ripening. Eur. Food Res. Technol. 237: 555-564.

González-Centeno, M. R., M. Jourdes, A. Femenia, S. Simal, C. Rosselló and P. L. Teissedre, 2012. Proanthocyanidin composition and antioxidant potential of the stem winemaking byproducts from 10 different grape varieties (Vitis vinifera L.). J. Agric. Food Chem. 60: 11850-11858.

González-Centeno, M. R., M. Jourdes, A. Femenia, S. Simal, C. Rosselló and P. L. Teissedre. 2013. Characterization of polyphenols and antioxidant potential of white grape pomace byproducts (Vitis vinifera L.). J. Agric. Food Chem. 61: 11579-11587.

González-Centeno, M. R., C. Rosselló, S. Simal, M. C. Garau, F. López and A. Femenia. 2010. Physico-chemical properties of cell wall materials obtained from ten grape varieties and their byproducts: Grape pomaces and stems. LWT-Food Sci. Technol. 43: 1580-1586.

Chamorro, S., A. Viveros, C. Centeno, C. Romero, I. Arija and A. Brenes. 2012. Effects of dietary grape seed extract on growth performance, amino acid digestibility and plasma lipids and mineral content in broiler chicks. Animal. 7: 555-561.

Chamorro, S., A. Viveros, A. Rebolé, B. D. Rica, I. Arija and A. Brenes. 2015. Influence of dietary enzyme addition on polyphenol utilization and meat lipid oxidation of chicks fed grape pomace. Food Res. Int. 73: 197-203.

Iqbal, Z., Z. Kamran, J. I. Sultan, A. Ali, S. Ahmad, M. I. Shahzad and M. U. Sohail. 2015. Replacement effect of Vitamin E with grape polyphenols on antioxidant status, immune, and organs histopathological responses in broilers from 1- to 35-d age. J. Appl. Poult. Res. 24: 127-134.

Ivanišová, E., A. Kántor, H. Frančáková and M. Kačániová. 2018. Phytochemical and Antioxidant Activity of Different Varieties of Grape Cultivated in Slovakia. In: Proceedings of the $8^{\text {th }}$ International Conference on the Quality and Safety in Food Production Chain, 20-21 June 2018. Wrocław University of Environmental and Life Sciences, Wrocław, Poland.

Kammerer, D. R., A. Schieber and R. Carle. 2005. Characterization and recovery of phenolic compounds from grape pomace: $A$ review. J. Appl. Bot. Food Qual. 79: 189-196.

Kardel, M., F. Taube, H. Schulz, W. Schütze and M. Gierus. 2013. Different approaches to evaluate tannin content and structure of selected plant extracts-review and new aspects. J. Appl. Bot. Food Qual. 86: 154-166.

Ky, I., B. Lorrain, N. Kolbas, A. Crozier and P. L. Teissedre. 2014. Wine by-products: Phenolic characterization and antioxidant activity evaluation of grapes and grape pomaces from six different French grape varieties. Molecules. 19: 482-506.

Liu, L. L., J. H. He, H. B. Xie, Y. S. Yang, J. C. Li and Y. Zou. 2014. Resveratrol induces antioxidant and heat shock protein mRNA expression in response to heat stress in black-boned chickens. Poult. Sci. 93: 54-62.
Llobera, A. and J. Cañellas. 2007. Dietary fibre content and antioxidant activity of Manto negro red grape (Vitis vinifera): Pomace and stem. Food Chem. 101: 659-666.

Makris, D. P., G. Boskou, N. K. Andrikopoulos and P. Kefalas. 2007. Characterisation of certain major polyphenolic antioxidants in grape (Vitis vinifera cv. Roditis) stems by liquid chromatography-mass spectrometry. Eur. Food Res. Technol. 226: 1075-1079.

Manterola, H., D. Cerda, E. Porte, C. Machado, L. Sirhan and J. Mohr. 1997. Study of the productive behavior and ruminal parameter variations in steers fed different levels of grape marc. Av. Prod. Anim. 22: 71-80.

Moate, P. J., S. R. O. Williams, V. A. Torok, M. C. Hannah, B. E. Ribaux, M. H. Tavendale and W. J. Wales. 2014. Grape marc reduces methane emissions when fed to dairy cows. J. Dairy Sci. 97: 5073-5087.

Molina-Alcaide, E., A. Moumen and A. I. Martín-García. 2008. Byproducts from viticulture and the wine industry: Potential as sources of nutrients for ruminants. J. Sci. Food Agric. 88: 597604.

Negro, C., L. Tommasi and A. Miceli. 2003. Phenolic compounds and antioxidant activity from red grape marc extracts. Bioresour. Technol. 87: 41-44.

Nicodemus, N., J. García, R. Carabaño and J. C. De Blas. 2007. Effect of substitution of a soybean hull and grape seed meal mixture for traditional fiber sources on digestion and performance of growing rabbits and lactating does. J. Anim. Sci. 85: 181-187.

Nielsen, B. and H. Hansen. 2004. Effect of grape pomace rich in flavonoids and antioxidants on production parameters in dairy production. J. Anim. Feed Sci. 13: 535-538.

Nishizawa, M., M. Kohno, M. Nishimura, A. Kitagawa and Y. Niwano. 2005. Non-reductive scavenging of 1,1-diphenyl-2-picrylhydrazyl (DPPH) by peroxyradical: A useful method for quantitative analysis of peroxyradical. Chem. Pharm. Bull. 53: 714-716.

Peiretti, P. G., G. Masoero and S. Tassone. 2017. Comparison of the nutritive value and fatty acid profile of the green pruning residues of six grapevine (Vitis vinifera L.) cultivars. Livest. Res. Rural. Dev. 29: 1-10.

Reščič, J., M. Mikulič-Petkovšek and D. Rusjan. 2016. The impact of partial dehydration on grape and wine chemical composition of white grapevine (Vitis vinifera L.) varieties. Eur. J. Hortic. Sci. 81: 310-320.

Rockenbach, I. I., E. Rodrigues, L. V. Gonzaga, V. Caliari, M. I. Genovese, A. E. Gonçalves and R. Fett. 2011. Phenolic compounds content and antioxidant activity in pomace from selected red grapes (Vitis vinifera L. and Vitis labrusca L.) widely produced in Brazil. Food Chem. 127: 174-179.

Russo, V. M., J. L. Jacobs, M. C. Hannah, P. J. Moate, F. R. Dunshea and B. J. Leury. 2017. In vitro evaluation of the methane mitigation potential of a range of grape marc products. Anim. Prod. Sci. 57: 1437-1444.

Shinagawa, F. B., F. C. de Santana, E. Araujo, E. Purgatto and J. Mancini-Filho. 2017. Chemical composition of cold pressed Brazilian grape seed oil. Food Sci. Technol. 38: 164-171.

Spigno, G., L. Maggi, D. Amendola, M. Dragoni and D. M. De Faveri. 2013. Influence of cultivar on the lignocellulosic fractionation of grape stalks. Ind. Crops Prod. 46: 283-289.

Tortuero, F., J. Rioperez, C. Cosin, J. Barrera and M. L. Rodriguez. 1994. Effects of dietary fiber sources on volatile fatty acid production, intestinal microflora and mineral balance in rabbits. Anim. Feed Sci. Technol. 48: 1-14.

Verhelst, R., M. Schroyen, N. Buys, and T. Niewold. 2014. Dietary 
polyphenols reduce diarrhea in enterotoxigenic Escherichia coli (ETEC) infected post-weaning piglets. Livest. Sci. 160: 138-140.

Wang, M. L., X. Suo, J. H. Gu, W. W. Zhang, Q. Fang and X. Wang. 2008. Influence of grape seed proanthocyanidin extract in broiler chickens: Effect on chicken coccidiosis and antioxidant status. Poult. Sci. 87: 2273-2280.

Xia, E. Q., G. F. Deng, Y. J. Guo and H. B. Li. 2010. Biological activities of polyphenols from grapes. Int. J. Mol. Sci. 11: 622-646.

Yan, L. and I. H. Kim. 2011. Effect of dietary grape pomace fermented by Saccharomyces boulardii on the growth performance, nutrient digestibility and meat quality in finishing pigs. Asian-Australas. J. Anim. Sci. 24: 1763-1770.

Zalikarenab, L., R. Pirmohammadi and A. Teimuriyansari. 2007. Chemical composition and digestibility of dried white and red grape pomace for ruminants. J. Anim. Vet. Adv. 6: 1107-1111.

Zarei, M. and P. Shawrang. 2016. Correlation between condensed tannin and fiber contents of irradiated pomegranate seed. Int. J. Agric. Sci. Belgrade. 61: 343-357. 